\title{
Deusa e/ou bruxa? \\ Uma análise dos dizeres sobre o feminino ontem e hoje
}

\author{
Goddess and/or Witch? \\ An analysis of the discourses about the feminine yesterday and today
}

\author{
Elaine Pereira Daróz ${ }^{1}$ \\ Dantielli Assumpção Garcia ${ }^{2}$ \\ Lucília Maria Abrahão e Sousa ${ }^{3}$
}

\section{RESUMO}

Filiados à Análise de Discurso (Pêcheux), propomos uma análise dos dizeres sobre a mulher presentes no romance português $A$ dama pé de cabra, que se atualizam nos jornais jornalístico (online), para compreendermos o lugar dessa memória sobre a mulher na esfera social.

PALAVRAS-CHAVE: Análise de Discurso. Mídia. Mulher. Memória.

\section{ABSTRACT}

In the light of the theoretical assumptions of Discourse Analysis (Pêcheux), we propose an analysis of the discourses about women, present on the Portuguese novel The lady of the goat, and updated in online journalistic discourse, in order to understanding of the imaginary about women on the social sphere.

KEYWORDS: Discourse Analysis. Media. Woman. Memory.

$$
* * *
$$

\footnotetext{
${ }^{1}$ Pós-doutoranda no Programa de Pós.Graduação em Psicologia da Universidade de São Paulo/FFCLRP (Apoio FAPESP Proc no 2018/13017-2). Pesquisadora dos Grupos "Discurso e memória: movimentos do sujeito e do E-1@dis - sujeito, rede eletrônica e sentidos em movimentos.ORCID ID: https://orcid.org/0000-0001-6084-7850 E-mail: lainedaroz@gmail.com. Universidade de São Paulo/FFCLRP.

2 Docente do Programa de Pós-Graduação em Letras. E-mail: dantieligarcia@gmail.com. ORCID: https://orcid.org/0000-0002-8834-2253 E-mail:dantielligarcia@gmail.com. Universidade Estadual do Oeste do Paraná - UNIOESTE.

${ }^{3}$ Docente na Universidade de São Paulo. Coordenadora do grupo de pesquisa "Discurso e memória: movimentos do sujeito", cadastrado junto ao Diretório de Grupos do CNPQ, e do E-1@dis - sujeito, rede eletrônica e sentidos em movimentos. Bolsista de produtividade CNPQ. Membro do Fórum do Campo /SP. ORCID: https://orcid.org/0000-0002-4585-9287 E-mail: luciliamsr@uol.com.br. Universidade de São Paulo/FFCLRP.
} 


\section{Palavras iniciais}

A palavra, em certos meios sociais, especialmente, no que veremos mais adiante, é considerada feminina e, assim, complexa desde a sua gênese. Assim como a mulher, a palavra de mulher encerra em si o poder de gerar, de multiplicar sentidos. Poder incontestável que, produzindo, por vezes, certo estranhamento, atemoriza a muitos, fazendo dela, palavra-mulher, uma deusa e/ou uma bruxa. Inúmeros foram (e são) os dizeres sobre (e para) a mulher no decorrer dos tempos e das histórias (a serem) contados. E, assim, no entrelaçamento entre a história e a memória, que nos aportamos dos pressupostos teórico-analíticos da Análise do Discurso, fundada por Pêcheux, para pensarmos o modo de funcionamento desses dizeres na esfera social, tendo em vista as suas implicações nas práticas sociais.

Em nosso trabalho, tomamos os dizeres sobre mulheres em manifestações que ocorreram no Dia Internacional da Mulher ${ }^{4}$, nos anos de 2017 e 2018 no Brasil, em alguns portais de notícias brasileiros disponíveis online, para pensarmos os efeitos da regularização/naturalização desses dizeres na esfera social, tendo em vista o fenômeno da mundialização ${ }^{5}$ e o alcance da internet em escala global a partir do século XX. Considerando que história e memória

\footnotetext{
${ }^{4} \mathrm{O}$ Dia Internacional da Mulher é considerado um marco na conquista do espaço da mulher na esfera social que, tendo como uma de suas demandas o direito ao voto, permitiu, ainda, um olhar mais atento às lutas pela equiparação de direitos no trabalho assim como na vida secular. Ver THE UNIVERSITY of Queensland. Fryer Library Online Exhibition. International Womens Day, 8th March. Disponível em $<$ http://web.archive.org/web/20080721222502/https://www.library.uq.edu.au/fryer/iwd/>. Acesso em 18 fev. 2019. Como mostramos em Garcia e Sousa (2014, p. 176), "Em 1975, a ONU declarou a década de 1975 a 1985 como a Década da Mulher e reconheceu o 08 de março como o Dia Internacional da Mulher. Em 1977, a Organização das Nações Unidas para a Educação, a Ciência e a Cultura (Unesco) reconhece oficialmente essa data como Dia da Mulher, em homenagem às 129 operárias queimadas vivas. Houve, por esse gesto da Unesco, a oficialização do Dia Internacional da Mulher como um evento em que se rememoram as greves/os incêndios do início do século XX. Embora haja diversas críticas teóricas acerca dessa relação greve-incêndio-Dia Internacional da Mulher, a Unesco legitima a data e faz circular um discurso que apaga as lutas feministas de séculos. Assim, o dia 08 de março passa a ser o Dia Internacional da Mulher".

${ }^{5}$ Ao trazermos o termo mundialização, do francês mondialisation, buscamos uma distanciação dos sentidos aparentemente evidentes acerca de uma globalização de dados e povos, visto que, a nosso pensar, trazem em si um apagamento da historicidade nas quais se fundam as culturas, produzindo um efeito de homogeneização nos sujeitos contemporâneos.
} 
se entrelaçam, ocupam um papel relevante na estruturação e na naturalização dos discursos, tomamos, ainda, o romance português $A$ dama pé de cabra, de Alexandre Herculano. Por meio de um gesto de análise do modo como os discursos sobre as mulheres são tecidos, levamos em atenção às repetições e/ou deslizamentos dos sentidos que se materializam nesses dizeres, bem como as condições sócio-histórico-ideológicas em que estes dizeres foram produzidos. Em nossas análises, consideramos as diferentes materialidades discursivas produzidas em momentos sócio-históricos distintos, produzindo um gesto de interpretação acerca desses dizeres e os efeitos da regularização desses sentidos nas práticas sociais.

\section{Entre a história e a memória: o lugar da mídia na regularização dos sentidos sobre a mulher}

A relação íntima entre a história e a memória é contada pelos gregos, fazendo delas figuras emblemáticas de sua mitologia. Sendo a Memória (Mnemosyne), a portadora de toda a sabedoria e, portanto, norteadora dos acontecimentos vindouros, gera a História (Clio), incumbida, então, de registrar e divulgar as realizações (ROSÁRIO, 2002). Nessa relação, a Memória estava muitas vezes ligada ao arcabouço de experiências apreendidas no passado, e a sua divinização tinha um caráter utilitário não apenas de imortalizar os acontecimentos sociais, como também o poder de transformar a história. Corroborando a relevância da memória na esfera social, para Pêcheux (1988), ela tem uma função estruturadora dos discursos, na medida em que opera como uma base para dizeres vindouros. Isso porque, segundo o autor, é no encontro da língua com a História que os sentidos são (re)construídos, sendo possível tanto a retomada de dizeres /sentidos, pela via da reprodução, quanto a sua atualização.

Em O papel da memória, estudo apresentado no colóquio História e Linguística em 1983, o autor afirma que a retomada dos sentidos pode se realizar por meio de pré-construídos, sentidos já-ditos anteriormente alhures, 
ou ainda por atravessamento de sentidos no fio do discurso. Segundo o autor (PÊCHEUX, 1999), enquanto o atravessamento de sentidos se realiza no nível da constituição dos dizeres, o pré-construído se materializa no discurso sob a forma de citações, paráfrases dentre outras. Seja na Literatura, nas Artes, no discurso jurídico, desde outrora inúmeros dizeres falam sobre a mulher, cujos sentidos se inscrevem em conformidade com cada tempo, cada povo, cada sociedade. Como afirma Perrot,

Há muito que as mulheres são as esquecidas, as sem voz da História. O silêncio que as envolve é impressionante. Pesa primeiramente sobre o corpo, assimilado à função anônima e impessoal da reprodução. O corpo feminino, no entanto, é onipresente: no discurso dos poetas, dos médicos ou dos políticos; em imagens de toda natureza - quadro, esculturas, cartazes - que povoam as nossas cidades. Mas esse corpo exposto, encenado, continua opaco. Objeto do olhar e do desejo, fala-se dele. Mas ele se cala. As mulheres não falam, não devem falar dele. $\mathrm{O}$ pudor encobre seus membros ou lhes cerra os lábios é a própria marca da feminilidade. (PERROT, 2003, p. 13)

Na Idade Média ${ }^{6}$, um olhar sobre o corpo feminino foi também produzido. Os dizeres sobre a mulher se ancoravam comumente no discurso religioso, regularizando, assim, uma memória do dizer sobre o feminino, ou seja, uma base discursiva para discursos vindouros.

Em A dama pé de cabra, romance português, Herculano revisita o conto medieval A dama do pé de cabra, fazendo retomar determinados sentidos sobre a mulher a saber, seu lado de bruxa, pecador, traidor. Nesse processo de reprodução de sentidos, o narrador interpela o leitor por meio de um diálogo mais íntimo, estabelecendo, assim, uma proximidade com o seu público:

\footnotetext{
${ }^{6}$ Retomamos aqui a Idade Média porque é esse o período histórico revisitado em $A$ dama pé de cabra. 
Vós os que não credes em bruxas, nem em almas penadas, nem em tropelias de Satanás, assentai-vos aqui ao lar, bem juntos ao pé de mim, e contar-vosei a história de D. Diogo Lopes, senhor de Biscaia. E não me digam no fim: "Não pode ser." Pois eu sei cá inventar cousas destas? Se a conto, é porque a li num livro muito velho, quase tão velho como o nosso Portugal. E o autor do livro velho leu-a algures ou ouviu-a contar, que é o mesmo, a algum jogral em seus cantares. É uma tradição veneranda; e quem descrê das tradições lá irá para onde o pague (HERCULANO,s/d, p. 2)

Sob o efeito de evidências dos sentidos relativamente estabilizados na esfera social - visto que advindos de uma tradição - o narrador busca advertir o seu leitor a crer na história a ser contada. A narrativa transcorre tendo D. Diogo, nobre senhor dono de terras, encantado por uma bela e atraente mulher, mas pagã e, portanto, com hábitos incomuns aos cristãos. Contraindo matrimônio com a bela Dama pé de cabra, tiveram um casal de filhos, D. Inigo e Dona Sol. No entanto, não sem acordos ocorreu o enlace, dentre eles, à prova de seu amor, advertiu a bela dama cujo nome não se diz: "O de que eu quero que te esqueças é o sinal da cruz: o que eu quero que me prometas é que nunca mais hás-de persignar-te." (HERCULANO,s/d, p. 3). Com uma narrativa repleta de elementos advindos da cultura judaico-cristã - como perdão, juramento, persignação x maldição, Deus x diabo, dentre outros, todos eles a inscrever efeitos de uma memória da dualidade corpo e alma, pecado e salvação - a história se desenrola de forma a salientar os poderes sobrenaturais da dama e o seu feitiço sobre o nobre senhor, salientando, ao final, os danos dessa relação pecaminosa, visto que pagã, trazendo ao nobre homem e seus descendentes, a ruína familiar e a condenação aos portais do inferno. Marcamos aqui um modo de funcionamento da memória sobre o feminino desde a narrativa mítica de Eva, aquele em que a mulher está associada ao pecado e ao mundo pagão, a escolhas consideradas erradas que levam à perdição da alma. Na narrativa, D. Diogo e D. Inigo, seu filho, lutam para escapar das garras da dama que se transfigura em belzebu, ao passo que D. 
Sol, a filha, é levada por sua mãe, e desaparece. (HERCULANO, s/d). Como podemos observar, o narrador se ancora no discurso religioso a fim de atentar ao leitor aos perigos de confiar nas palavras de uma mulher, sob a pena de trazer para si, maldição para si, bem como para a sua família. Nesses termos, palavra de mulher é aquela que inscreve os sentidos de maledicência, perigo e traição; o que a título de passagem também esteve ligado ao universo das mulheres ditas feiticeiras no medievo, aquelas que discursivizavam as composições químicas que hoje sabemos serem pertinentes, aquelas que liam a natureza de modo diferente e ousavam usar a razão para construir um certo modo de olhar o mundo.

Sob uma aparente evidência desses dizeres, Herculano reproduz sentidos acerca de uma relação antagônica entre homem e mulher, regularizando uma memória do dizer sobre a mulher que traz em si um mal que lhe é constitutivo. Tais sentidos se materializam no conto medieval, não apenas pela narrativa, mas pela escolha lexical em seu título que, intitulado A dama do pé de cabra (grifo nosso) - ou seja, a dama que tinha os pés forcados como os de cabra, sendo este um atributo físico da dama - passa a ser A dama pé de cabra (grifo nosso), trazendo nessa escolha um ad-junto a essa mulher, isto é, algo que é da sua constituição. Sendo assim, por meio de um atravessamento de sentidos, Herculano promove uma atualização de uma memória do dizer sobre a mulher em relação à lenda medieval, fazendo intervir mais uma vez o discurso religioso no qual a mulher, Eva, traz em si a desobediência - o mal, portanto - sendo a responsável por introduzir o pecado no mundo. Eva é aquela que prova o sabor e o saber proibidos, desobedece à ordem insana e desafia os efeitos de tocar e conhecer a natureza, o preço a ser pago por ela é absurdamente alto e condenatório, visto que o que se espera de uma mulher é a submissão cega e inquestionável.

Segundo Pêcheux (1988), os discursos não são neutros, visto que neles se materializam a ideologia condizente com a ordem ditada. Por meio da reprodução de sentidos acerca do binômio culpa/punição, o silenciamento do nome da dama contribui para esse imaginário do feminino contribui para uma 
padronização do comportamento dos sujeitos de acordo com valores cristãos de um país católico (Portugal) no século XIX, com vistas ao silenciamento da mulher na esfera social. É pelo viés da repetibilidade, conforme postula o autor (PÊCHEUX,1988), que a ideologia opera o efeito de evidência dos sentidos, tendo em vista a sua naturalização no seio social. Recurso este próprio do discurso midiático, a fim de convencer, persuadir o seu públicoalvo. Embora o romance português remonte a Portugal do século XIX, a narrativa ganhou visibilidade mundial com a sua divulgação pela rede mundial de computadores, possibilitando diferentes gestos de interpretação para o romance por meio do acesso por uma diversidade de povos e culturas.

Em especial a partir do século XX, com o aperfeiçoamento das tecnologias e a democratização do computador e, em especial o acesso à internet aliada à mundialização, os dizeres em circulação na esfera social ganharam novos contornos e a mídia, um papel preponderante na atualidade, na medida em que, por infovias próprias do mundo digital, é capaz de ultrapassar as barreiras espaço-geográficas. A se valer do jogo de imagens, a mídia faz circular inúmeros dizeres em diferentes espaços de enunciação TV, outdoor, rádio, internet - com vistas ao controle dos sentidos prédeterminados.

$\mathrm{Na}$ aurora do século XXI, com a velocidade das informações aliada ao seu alcance em escala mundial, a mídia, particularmente a digital, exerce grande poder interpelatório aos sujeitos contemporâneos, fazendo com que determinados dizeres retomem aos leitores, em suas variadas formas hiperlinks, textos, links, vídeos, memes - produzindo um efeito de evidência dos sentidos ali inscritos. Uma das especificidades da Análise de Discurso é o questionamento da evidência dos sentidos, considerando que a ideologia se materializa na linguagem, tendo como uma de suas funções convocar os sujeitos a ocuparem os seus lugares ideologicamente pré-determinados na esfera social. Nesse processo, determinados sentidos são retomados, condizentes com os interesses da ideologia vigente, enquanto outros são silenciados. 
Considerando que a mídia opera não apenas na regularização dos dizeres, mas assume um lugar preponderante na produção de sentidos na atualidade, desambiguizando os sentidos que poderiam ser atribuídos ao mundo (MARIANI, 1996), propomos, a seguir, um gesto de análise sobre (e para) a mulher postos em circulação no discurso jornalístico, na modalidade online, no Dia Internacional da Mulher, para uma melhor compreensão do modo de funcionamento dos sentidos na regularização de uma memória do dizer sobre a mulher na atualidade.

Como mostraremos na continuidade de nosso texto, há, no discurso midiático que tomamos como objeto de análise, uma retomada dessa memória que relaciona a mulher com traições, desobediências, pecados, com o não recato e a docialidade. Na narrativa ficcional que trouxemos à análise, teríamos, de certo modo, um imaginário, pelo trabalho e funcionamento do poético, que cria um dizer sobre o que é ou não ser mulher e como deve essa agir ou não. No registro midiático, embora as mulheres trazidas ao texto sejam "mulheres reais", estejam na rua, em movimentos sociais de mulheres, apagam-se suas diferenças e sustentam-se ainda os dizeres que o texto literário ficcionalizou: a mulher é capaz de trair, mentir, manipular, seduzir, (di)simular. Em síntese, é ela culpada e, por isso, merece punição, castigo, merece ter em seu rosto a marca de um hematoma que registra na pele sua responsabilidade histórica por não ser dócil e recatada.

\section{A mulher no discurso jornalístico: um gesto de análise ${ }^{7}$}

Acerca da relevância da mídia na atualidade, Mcchesney (2003, p. 217) afirma que "a globalização econômica e cultural seria claramente impossível sem um sistema de mídia comercial global para promover os mercados globais e encorajar os valores de consumo". Considerando que todos os discursos são

\footnotetext{
${ }^{7}$ No artigo "D(n)os sentidos que se marcam nos dizeres de ontem e hoje: a (r)existência da mulher" (no prelo), apresentamos também algumas reflexões no que tangem aos dizeres sobre a mulher no discurso jornalístico.
} 
ideológicos, estudar a mídia numa abordagem discursiva, como afirma Romão,

nos permite refletir sobre as regiões de sentido tidas como legítimas e verdadeiras, questionando os sentidos dominantes definidos como verdade absoluta e como retrato objetivo da realidade; indagando as palavras (e as sombras delas) sustentadoras de um modo de dizer, que é apresentado como confiável e único possível de ser dito; interpretando os processos de naturalização de dizeres que servem a projetos e hegemonias e, por fim, inscrevendo uma escuta de como as sombras das palavras significam e fazem falar efeitos de sentido que reclamam interpretação. (ROMÃO, 2007, p. 220)

Sob o efeito de linearidade dos sentidos, o discurso midiático, e em especial o jornalístico, faz circular modo(s) específico(s) de enunciar os acontecimentos sob a forma de reportagens, vídeos, entrevistas que, no espaço digital, ganham maior visibilidade a um público variado. Das palavras e as suas sombras, como nos diz a autora (ROMÃO, 2007) interessa-nos uma melhor compreensão dos sentidos que se inscrevem nos dizeres sobre a mulher postos em circulação no seio social. Sentidos esses que, muitas vezes apesar de não-ditos explicitamente no texto, trazem marcas no discurso, regularizando determinados sentidos sobre (e para) a mulher na atualidade. Por isso, não apenas a palavra em si, mas o discurso é pensado discursivamente como "efeito de sentidos", visto que os sentidos se estabelecem na relação entre o sujeito e a língua, ou seja, estão sempre em curso.

Em especial no discurso jornalístico, os acontecimentos são muitas vezes postos em circulação, quer sob a forma de relatos, de entrevistas, de cobertura de eventos etc, reproduzindo determinados sentidos sob um efeito de verdade, cunhado por uma legitimidade da instituição a que se filia. No portal de notícias $G 1$, de grande notoriedade e veiculado na modalidade 
online, observamos a cobertura do Dia Internacional da Mulher ${ }^{8}$, que traz à cena a manifestação das mulheres por seus direitos, como podemos observar a seguir.

\section{Figura 1}

Mulheres fazem manifestação contra violência em praça de Cuiabá A organização do ato e a PM não estimaram o número de participantes.

Em 2016, mais de 40 mil casos de violência contra a mulher foram registrados Protesto ocorreu nesta quarta-feira (8), na Praça Ipiranga, no Centro de Cuiabá

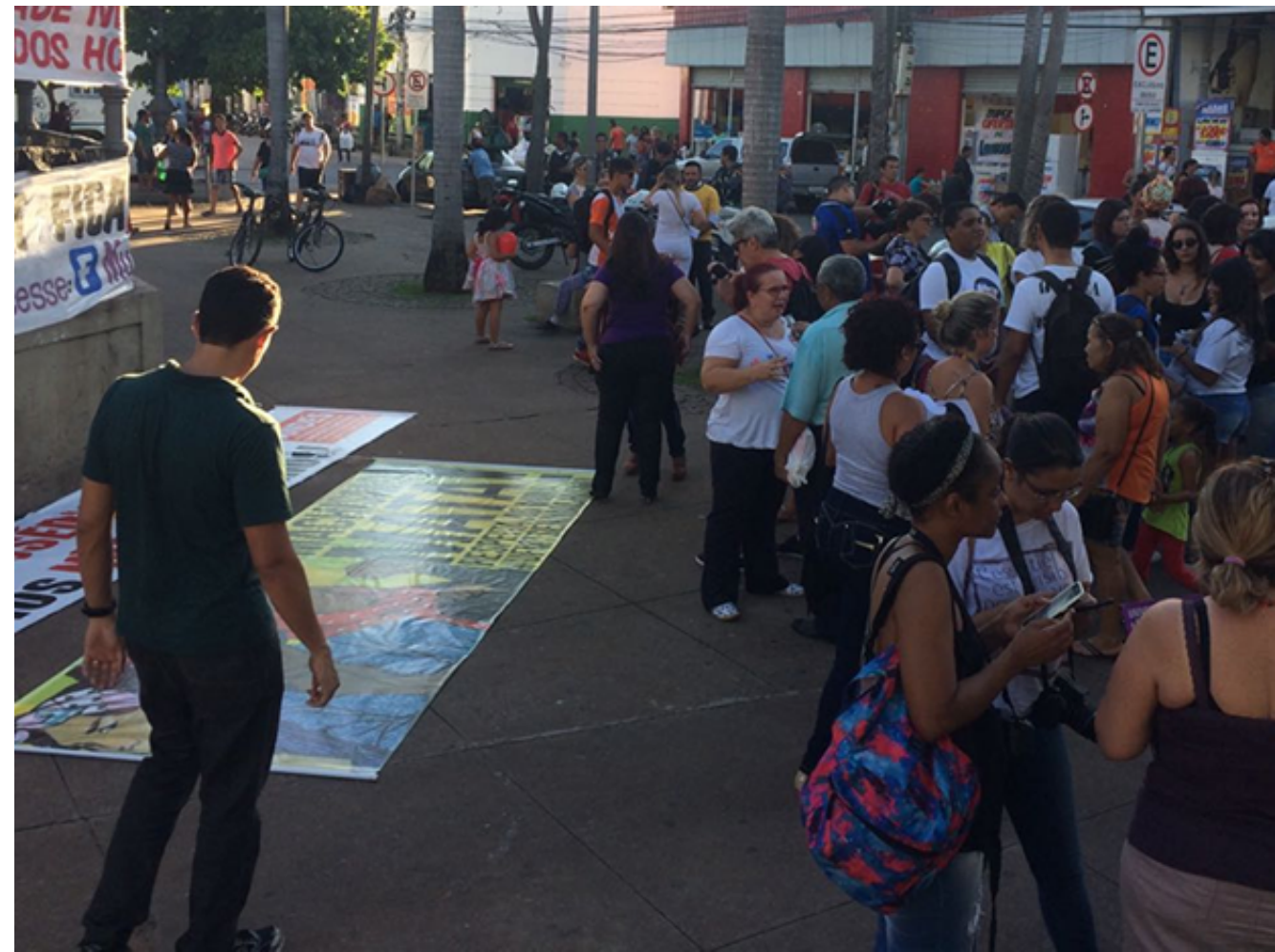

Foto: André Souza/G19

Além dos dizeres em destaque no olho da reportagem, a imagem também nos convida a compreender os sentidos sobre (e para) a mulher que

\footnotetext{
${ }^{8}$ Essa reportagem se refere à cobertura jornalística do Dia Internacional da Mulher, no ano de 2017, período em que iniciamos a coleta dos dados. Ver SOUZA, André. Mulheres fazem manifestação contra violência em praça de Cuiabá. G1, Cuiabá, 8 mar. 2017. Disponível em $<$ http://g1.globo.com/matogrosso/noticia/2017/03/mulheres-fazem-manifestacao-contra-violencia-em-praca-de-cuiaba.html> . Acesso em 27 dez. 2018.

${ }^{9}$ SOUZA, André. Mulheres fazem manifestação contra violência em praça de Cuiabá. G1, Cuiabá, 8 mar. 2017. Disponível em $<$ http://g1.globo.com/mato-grosso/noticia/2017/03/mulheres-fazem-manifestacaocontra-violencia-em-praca-de-cuiaba.html>. Acesso em 27 dez. 2018.
} 
se inscrevem nesses dizeres. Embora a reportagem se realize a fim de colocar em destaque o movimento das mulheres nesse dia memorável, observamos, na Figura 1, um direcionamento de sentidos acerca de um imaginário da mulher contemporânea, consciente dos seus direitos e que reivindica suas demandas. Na imagem cuidadosamente captada pelo fotógrafo, observamos que um homem é evidenciado, solitário, com os olhos fitos no chão, aparentemente cabisbaixo face às necessidades das mulheres, materializadas em cartazes na rua. A nosso pensar, o homem de costas para o fotógrafo, aliado ao seu afastamento das mulheres em manifestação, produzem um efeito de vitimização do homem face o movimento de luta dos direitos das mulheres.

Sob essas mesmas lentes, as mulheres são postas em segundo plano, ainda na Figura 1. Neste movimento de luz e sombras proporcionado pelo ângulo das lentes fotográficas, produz-se um efeito de homogeneização dos participantes como uma massa amorfa, em apagamento das peculiaridades do movimento de luta das (e para) as mulheres na atualidade. Sob esse efeito, produz-se uma invisibilização dessas mulheres na formação social, em apagamento das questões das e para as mulheres postas em jogo na manifestação. Para Davallon (2010, p. 28), "a imagem é utilizada em complementaridade ao enunciado linguístico para tornar presentes as qualidades e conduzir o leitor não só a se recordar, mas se posicionar em meio ao grupo social dos consumidores". E, assim, observamos que os sentidos inscritos nesta reproduzem uma imaginária relação antagônica entre homens e mulheres, na qual a luta pelos direitos das mulheres negligencia os deveres das mulheres perante o matrimônio, e o lar.

A organização do ato, como em destaque na reportagem, fere a ordem a ordem ditada, na qual cabe à mulher o espaço doméstico para o bem-estar da família. A se valer do jogo de aproximação-distanciamento do fotógrafo em cobertura jornalística acerca do Dia Internacional da Mulher, em confluência com o enunciado linguístico disponível, o portal de notícias regulariza uma memória do dizer sobre a mulher, com vistas a uma tomada de posição dos 
sujeitos consumidores face a esses sentidos. Na cobertura jornalística é exposta, ainda, a manifestação das mulheres contra a violência, como podemos observar na Figura 2.

Figura 2

"... manifestantes simularam hematomas nos rostos com maquiagem"

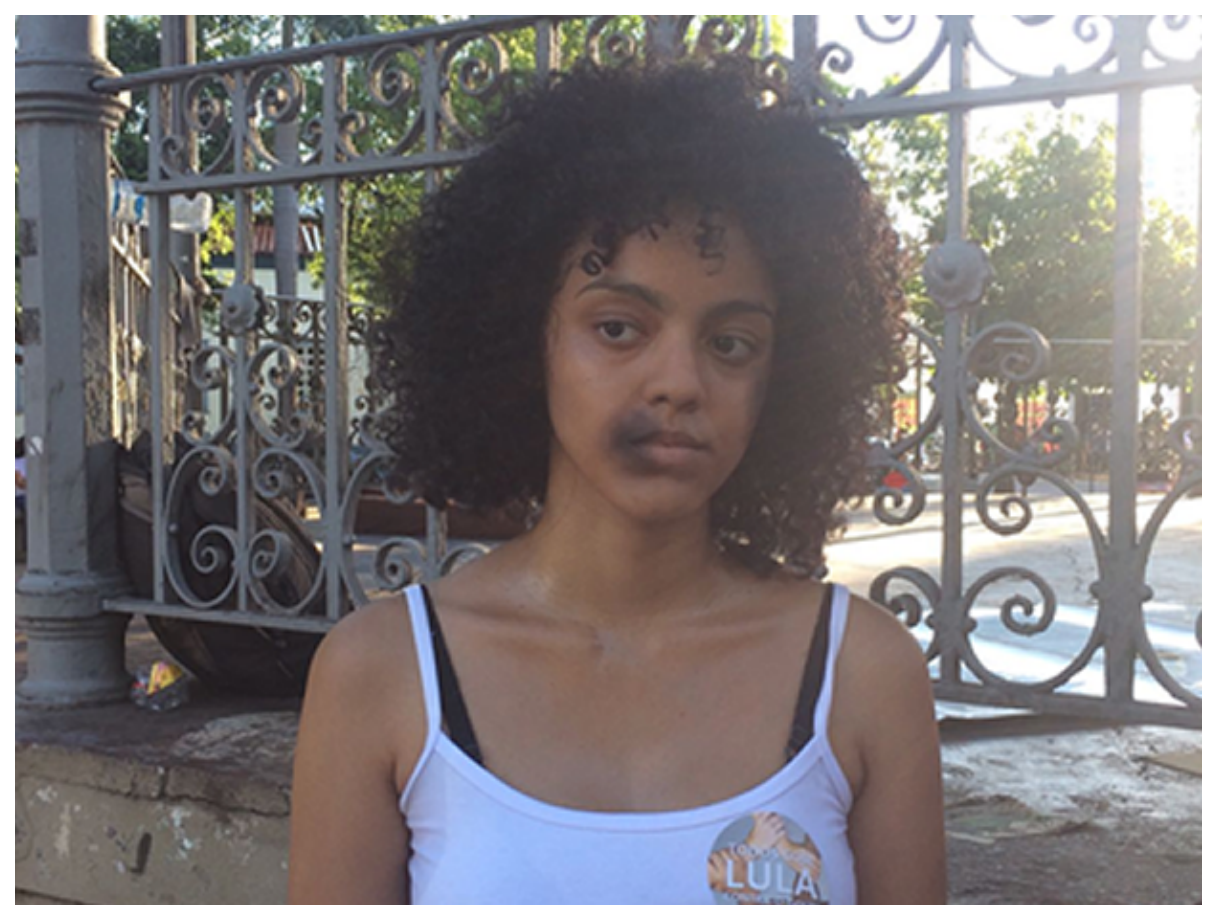

Foto: André Souza/G110

Na Figura 2 temos a representação (materialização) de uma das formas de violência sofrida pelas mulheres, a violência física sofrida por muitas delas (em especial no ambiente doméstico). Na cobertura jornalística, esta representação é tomada no dizer do repórter por uma simulação, observado no enunciado: "manifestantes simularam hematomas nos rostos com maquiagem" (grifo nosso). Indagamos aqui o que são "hematomas no rosto"? O que significa levar soco, murro ou apanhar na face? Quem bate no rosto da mulher, e por que no rosto de modo a publicizar a agressão? Ora, sabemos pelos registros discursivos da violência contra a mulher, que muitas são

\footnotetext{
${ }^{10}$ SOUZA, op.cit.
} 
humilhadas e subjugadas justamente nesse lugar em que a face está em jogo, a cara da mulher como índice de identidade singular. Receber a violência nesse lugar do corpo é sair à rua e mostrar de cara que foi vítima da mão masculina, ou seja, é seguir com uma assinatura de homem de cara. Ademais, pelo funcionamento de uma memória que culpabiliza a mulher pela violência que sofre, ter um hematoma na face também indicia que algo teria a mulher feito para ter seu rosto marcado. Na "simulação", no olhar baixo, a dúvida se não teria a "mulher merecido" a violência da qual foi vítima.

Discursivamente, compreendemos que a escolha das palavras na formulação do dizer não é desprovida do seu cunho ideológico, visto que é função da ideologia a naturalização de determinados sentidos, enquanto sentidos outros são silenciados, a fim de regularizar uma memória do dizer com vistas à instituição das práticas sociais (PÊCHEUX, 1988). Em especial na sociedade ocidental, a regularização da memória do dizer se marca pela dicionarização dos termos, numa tentativa de aprisionamento dos sentidos a serem lembrados. Nesse movimento de incorporação/assimilação dos sentidos, os sujeitos discursivos são convocados a tomarem os seus lugares na esfera social. Para melhor compreendermos o direcionamento dos sentidos que se marcam no dizer do repórter jornalístico, atentamos para as possibilidades de leituras para o verbo "simular", utilizado pelo repórter jornalístico na cobertura da matéria sobre o manifesto das mulheres.

Dentre os sentidos possíveis, encontramos disponíveis na rede mundial de computadores algumas das possibilidades de interpretação em um dicionário de sinônimos, derivando inclusive para o termo simulação: simular = Fingir ser real o que não é; representar; encenar; para simulação = falsidade, hipocrisia, dissimulação, artifício. ${ }^{11}$ Para 0 dicionário online Priberam, o verbo simular, como verbo transitivo (exige complemento, portanto) é o mesmo que "fingir, fazer o simulacro de, fazer

\footnotetext{
11 DICIONÁRIO Priberam da Língua Portuguesa. Disponível em $<$ https://dicionario.priberam.org/consultar.aspx>. Acesso em 28 dez. 2018.
} 
parecer real (o que não é)", complementando as palavras relacionadas: simulamento, simulação, simuladamente, simulado. ${ }^{12}$

$\mathrm{Na}$ imagem da Figura 2, podemos observar que a mulher é fotografada com o olhar de esguelha ${ }^{13}$, sem olhar a câmera, nem o repórter fotográfico. $\mathrm{Na}$ cultura ocidental, o olhar é muitas vezes significado como o espelho capaz assim de revelar o mundo interior, isto é, os segredos da alma. Por esse prisma, regulariza-se uma memória no seio social de um dizer de verdade posto em relação à capacidade de fitar os olhos do seu interlocutor; e, doutra forma, tomado como um dizer de mentira o sujeito que não fita os olhos do seu interlocutor ao enunciar. Tomando em atenção a confluência dos elementos linguísticos que, lembramos, aqui nos interessa o verbo simular, à imagem da mulher com o olhar desconfiado, observamos um direcionamento de sentidos ao imaginário de uma mulher supostamente incapaz de fitar a câmera, sendo este um dos sintomas do seu fingimento e dissimulação.

Enquanto o olhar do leitor desta matéria jornalística fita a imagem da mulher, chama-nos a atenção o colo à mostra dos seios em camiseta regata, sutiã aparente e, por fim, as marcas de uma violência física contra a mulher. Em atenção às condições de produção do discurso da mídia nesta matéria jornalística, observamos que, por um deslizamento de sentidos, se marca no dizer do repórter uma posição machista (e perversa) perante a causa das mulheres, na e pela qual as mulheres simulam, "fingem ser realidade" a violência doméstica, em seus diferentes níveis, retomando uma memória do dizer da negação desta violência na formação social, ou até mesmo uma justificativa (i)lógica para tal, em apagamento da dor sentida por essas mulheres. Por essa via, o dizer do repórter traz à memória o imaginário de mulher constitutivamente pecaminosa, trazendo à cena uma suposta

\footnotetext{
${ }^{12}$ Ao recorrermos aos dicionários na versão online, tomamos em atenção a abrangência dessas informações no ambiente virtual, alcançando um público heterogêneo com diferente classe social, sexo, idade, cultura etc.

${ }^{13}$ Mais uma vez recorremos ao dicionário na versão online para compreendermos o tipo de olhar que se materializa na imagem da mulher, apreendendo dele os sentidos possíveis. De acordo com o Dicionário Informal, o termo designa um olhar desconfiado, de alguém que se sente ameaçado. Disponível em https://www.dicionarioinformal.com.br/olhar+de+esguelha/. Último acesso em 27 dez. 2018.
} 
habilidade, então constitutiva da mulher, de fingir, sendo este o seu mal que a constitui.

Embora o enunciado "manifestantes simulam hematomas" esteja na forma plural, a única mulher evidenciada na imagem, expressa na figura 2, traz um adesivo colado na blusa, junto ao seio da mulher, marcando, assim, uma posição político-partidária, significada na imagem pelo adesivo LULA o principal representante do Partido dos Trabalhadores no Brasil. Observamos assim, que o discurso jornalístico acerca dessa manifestação, direcionamento dos sentidos para um imaginário de mulher, em especial a mulher que se filia ao projeto político-partidário de esquerda, que finge, que mente e, por isso, não merece credibilidade, a respeito de qualquer reivindicação. Sentidos esses que respondem às demandas da ordem vigente de uma sociedade capitalista. Um dos pilares da sociedade capitalista é a tríade tempo-trabalho-lucro, que visa à profissionalização dos sujeitos nela inscritos, satisfazendo, assim, às demandas do mercado. Na reportagem, observamos que a instituição corrobora tais valores, trazendo no corpo da notícia destaque às manifestantes que possuem alguma formação profissional, ou está em vias de se profissionalizar. Efeito esse produzido pela nominalização dessas manifestantes, e a não-identificação de outras, como vemos a seguir.

“O dia 8 de março marca a memória da resistência feminina. Neste dia relembramos as mulheres que vieram antes de nós e, acima de tudo, reivindicamos os direitos que ainda são negados", declarou a psicóloga Naiana Gonçalves, de 22 anos (grifo nosso).

"Lutamos contra a violência física, o machismo, o racismo e também contra a violência do estado contra a mulher", afirmou Naiana. (grifo nosso)

E, ainda, em "Ainda somos vítimas da violência física que ainda continua fazendo vítimas em Mato Grosso, disse a estudante de serviço social Natalia Menezes". (grifo nosso). Como viemos afirmando, os discursos não são neutros, 
mas são produzidos a partir de escolhas de palavras/sentidos que vão sendo retomada(o)s com vistas à sua regularização. Nesse contexto, a nominalização produz um efeito de referencialidade simbólica (FEDATO, 2013), constituída em relação a uma memória do dizer, isto é, ao repetível da língua que se materializa no discurso, considerando o que deve ser lembrado e, assim, o que deve ser esquecido, condizente com os interesses da ideologia dominante. Ao identificar nominalmente e, sobretudo, indicar o estatuto social das entrevistadas selecionadas, observamos que o repórter - filiado aos sentidos ideológicos da instituição que representa - é afinado com os valores capitalistas e, portanto, em contraposição aos sentidos inerentes socialismo, comunismo e outras filiações ideológicas, ao qual a manifestante da Figura 2 se filia.

Em confluência entre os elementos linguísticos - textualmente materializados na reportagem - e os elementos extralinguísticos - que se materializam nas imagens das manifestantes - observamos que, ao destacar a profissionalização de algumas manifestantes, produz-se um efeito de deslegitimação do movimento enquanto luta pela garantia dos direitos das mulheres, visto que a manifestação ocorreu em uma quarta-feira - como em destaque na Figura 1 - e durante o dia - como podemos observar nos efeitos de luz e sombra das imagens nas Figuras 1 e 2 - período significado como comercial para trabalhadores e sociedade em geral. Dessa forma, colocam-se os direitos das mulheres em relação aos seus deveres, enquanto profissionais - como identificada na reportagem - ou mulheres significadas como do lar devido a sua não-profissionalização, negligenciando os afazeres domésticos historicamente a elas pré-determinados. Na sequência linguística que se marca a matéria jornalística, o repórter produz um relato que, entre aspas (“ "), ressalta o que designa como uma performance das manifestantes, como vemos a seguir:

Com cartazes e faixas, as manifestantes marcharam pela Avenida Tenente Coronel Duarte, a Prainha, em direção à Praça da República, no Centro de 
Cuiabá. No trajeto, uma performance "evocou os espíritos de mulheres que morreram por causa da violência" (aspas do autor - grifo nosso).

Dentre as possíveis leituras para o termo performance, estão: interpretação; exibição, apresentação, espetáculo, show, atuação, interpretação, representação. ${ }^{14}$ Observamos que a escolha do termo, seguido de uma afirmação marcada por aspas (“"), de cunho religioso, possibilita um efeito de não-credibilidade à prática religiosa, que distingue dos valores judaicocristãos nos quais se afina, majoritariamente, o povo brasileiro. Nesse contexto, o marcador discursivo (“”) produz, ainda, um efeito de não-responsabilização jornalista acerca dos dizeres que ali se materializam.

No ano seguinte, em 2018, o Dia Internacional da Mulher continua a ser discursivizado no Brasil, assim como em boa parte dos países ocidentais. A rememorar a luta das mulheres pela equiparação dos seus direitos, o Jornal do Brasil, na sua modalidade online, também dedica uma matéria jornalística sobre o evento ao redor do mundo ${ }^{15}$. Embora a própria designação do jornal o direcione para o Brasil, observamos que os dizeres que nele se materializam abordam manifestações em diversos países, como: Espanha, Iraque, Alemanha, Egito; e silencia a manifestação em território brasileiro.

Numa abordagem discursiva, o discurso, pensado teoricamente, é concebido como efeito de sentidos, visto que os sentidos se estabelecem na relação entre sujeito e língua. Nesse processo de constituição /formulação /circulação dos sentidos a serem regularizados no seio social, implicam não só os sujeitos, mas também as condições sócio-históricas e ideológicas em que estão envolvidos na produção do dizer. Isto porque, segundo o autor Pêcheux (1988), é próprio da ideologia dissimular o seu funcionamento na linguagem sob o espectro de uma suposta neutralidade do dizer e transparência da

\footnotetext{
${ }^{14}$ Disponível em https://www.sinonimos.com.br/performance/. Acesso em 26 fev 2019.

${ }^{15}$ GREVES e manifestações ao redor do mundo pelos direitos das mulheres. Jornal do Brasil, Rio de Janeiro, $\quad 8 \quad$ mar. $2018 . \quad$ Disponível em $<$ https://www.jb.com.br/index.php?id=/acervo/materia.php\&cd_matia=886339\&dinamico=1\&preview= 1>. Acesso em 28 fev. 2019.
} 
linguagem. Assim, a tomada de posição do sujeito está intrinsecamente ligada a formações ideológicas a que ele se filia na produção do discurso.

Assim como o discurso não é neutro, o autor (PÊCHEUX, 1988) afirma que não há sujeito neutro, visto que a tomada de posição do sujeito no discurso é constitutiva da sua condição de ser sujeito, processo que se realiza na e pela língua(gem). Assim, consideramos que, ao silenciar as manifestações das mulheres em prol de suas demandas sociais, o jornal se filia ideologicamente a um discurso patriarcal, machista, muitas vezes exacerbado no Brasil, que se materializa em práticas de violência simbólica, e física, às mulheres no país, como afirmamos. Situação essa que, segundo pesquisas recentes ${ }^{16}$, denuncia um número crescente de feminicídio no país, mesmo após a instituição da Lei no 11.340 - Lei Maria da Penha - em $2016^{17}$.

Embora não seja aqui o nosso objeto de estudo, vale-nos uma questão relevante acerca dessa questão, trazendo à cena a historicidade inerente à criança dessa lei. A Lei Maria da Penha foi criada em 2015, a partir de um atentado sofrido por uma mulher do mesmo nome, cometido por seu marido na tentativa de matá-la. Sobrevivente desse acontecimento, a lei foi criada em prol de mulheres que sofrem agressões, físicas ou simbólicas, geralmente por seus companheiros ou homens próximos. A lei deu origem, ainda, à Lei $\mathrm{n}^{\circ}$

\footnotetext{
${ }^{16}$ Ver RIO DE JANEIRO. Instituto de Segurança Pública. Dossiê Mulher 2018. Disponível em $<\mathrm{http}: / /$ www.ispvisualizacao.rj.gov.br/Mulher.html>. Acesso em 5 mar. 2019. BUENO, Samira et all. Visivel e invisivel: a vitimização de mulheres no Brasil, 2 ed., 2019. São Paulo: Fórum Brasileiro de Segurança Pública, 2019. FERREIRA, Paula; CAPETTI, Pedro. Em dois anos, processos por feminicídio crescem 51\% em 13 estados do país. BRASIL. Senado Federal. Observatório da Mulher contra a Violência. Panorama da violência contra as mulheres no Brasil [recurso eletrônico]: indicadores nacionais e estaduais. n.2 (2018). Brasília: Senado Federal, Observatório da Mulher Contra a Violência, 2018. O Globo, Rio de Janeiro, 15 jan. 2019. Disponível em <https://oglobo.globo.com/sociedade/emdois-anos-processos-por-feminicidio-crescem-51-em-13-estados-do-pais-

23372788?utm_campaign=clipping_institucional_dia_a_dia\&utm_medium $=$ email\&utm_source $=\mathrm{RD}+\mathrm{St}$ ation>. Acesso em 5 mar. 2019.

${ }^{17}$ BRASIL. Presidência da República. Lei $n^{\circ} 11.340$, de 7 de agosto de 2006 - Cria mecanismos para coibir a violência doméstica e familiar contra a mulher, nos termos do § 80 do art. 226 da Constituição Federal, da Convenção sobre a Eliminação de Todas as Formas de Discriminação contra as Mulheres e da Convenção Interamericana para Prevenir, Punir e Erradicar a Violência contra a Mulher; dispõe sobre a criação dos Juizados de Violência Doméstica e Familiar contra a Mulher; altera o Código de Processo Penal, o Código Penal e a Lei de Execução Penal; e dá outras providências.Brasília: Presidência da República, 2006. Acerca da eficácia dessas iniciativas na sociedade brasileira, discorreremos mais amiúde acerca dessa questão em trabalhos futuros.
} 
13.104 - Lei do feminicídio ${ }^{18}$ - concebida na letalidade da mulher em contexto discriminatório. O número crescente de agressão às mulheres no país, apesar de iniciativas para combater esse tipo de violência, nos diz sobre a eficácia de tais medidas no intuito de coibir a violência no país.

Ao discorrer sobre As formas do silêncio, Orlandi (2007) afirma que, assim como as palavras, o silêncio também significa. Segunda a autora, é pelo silêncio constitutivo, aquele existente nas escolhas das palavras /sentidos a serem lembrada(o)s, que determinados sentidos retornam no dizer, fazendo silenciar sentidos outros possíveis. Nesse movimento em que sujeitos e sentidos se constituem, a memória ocupa um papel estruturante na regularização dos sentidos, produzindo os seus efeitos. A nosso pensar, os sentidos que direcionam para um silenciamento da mulher fazem calar as suas demandas na atualidade, corroborando o discurso patriarcal, em que pese uma sobreposição masculina, pela força inclusive, em contraponto a uma suposta debilidade feminidade.

Amparado pela instituição que o representa, o discurso jornalístico sobre o movimento em prol das mulheres, promove uma linearização desses sentidos por meio de um discurso circular, produzindo seus efeitos nos sujeitos contemporâneos. Acerca dos efeitos da internet nas relações sociais, Giorgenon; Abrahão Sousa \& Pacífico (2014) afirmam que o espaço cibernético funciona como um espaço de íntima conexão entre o sujeito contemporâneo e a realidade (virtual e física), por meio de um espelhamento de si, produzindo um deslumbramento no sujeito contemporâneo, como um efeito produzido pelo jogo de imagens alteridade ao outro e ao mundo de que o espaço cibernético é capaz.

Dentre os papéis que a literatura ocupa na esfera social, Facina (2004) destaca o enriquecimento intelectual e cultural de cada leitor. Sendo assim,

\footnotetext{
${ }^{18}$ BRASIL. Presidência da República. Lei $n^{\circ} 13.104$, de 9 de março de 2015 - Altera o art. 121 do DecretoLei no 2.848, de 7 de dezembro de 1940 - Código Penal, para prever o feminicídio como circunstância qualificadora do crime de homicídio, e o art. 1o da Lei no 8.072, de 25 de julho de 1990, para incluir o feminicídio no rol dos crimes hediondos. Brasília: Presidência da República, 2015.
} 
observamos que esta noção se firma numa concepção de cultura significada como a transmissão de valores e costumes herdados historicamente (BOAS, 2011). Consideramos que esta é uma concepção totalizante de cultura, e negligencia o caráter ideológico intrínseco a esses sentidos, com implicações nas práticas sociais. Numa abordagem discursiva, a cultura é compreendida como resultante da estabilização de já-ditos anteriormente - ideologicamente pré-determinados, portanto - que se materializam no discurso por meio de uma memória do dizer, produzindo a instituição/naturalização, condizentes com a ordem ditada.

Como vimos, deusa ou bruxa, culpada ou vítima, má ou dócil, a mulher é significada no decorrer da história da civilização ocidental a partir de um imaginário de feminino, regularizando uma memória do dizer sobre (e para) a mulher na atualidade. A nosso pensar, neste jogo este que se estabelece na língua - no discurso, portanto - a disputa pela regularização de determinados sentidos sobre o feminino possui implicações à posição sobre-determinada à mulher na atualidade. Ao nos debruçarmos sobre os sentidos sobre (e para) a mulher, em suas diferentes materialidades e condições de produção, buscamos uma des-naturalização desses sentidos, com vistas a uma melhor compreensão dos seus efeitos nas práticas dos sujeitos. Sob esse viés, apresentamos, a seguir, alguns apontamentos finais.

\section{Alguns apontamentos finais}

No encontro entre história e atualidade, a memória faz intervir sentidos estabilizados, produzindo (ou não) sentidos novos a partir de diferentes posições dos sujeitos, em suas diferentes realidades. A íntima relação entre Brasil e Portugal se marca historicamente, produzindo efeitos de sentidos distintos, mas nem sempre divergentes. Nas materialidades analisadas, observamos que - quer por silenciamento dos sentidos quer por um efeito parafrástico produzido pela reiteração de mesmos sentidos no fio do discurso - o discurso jornalístico no Brasil, em cobertura ao Dia Internacional 
da Mulher, corrobora com os dizeres sobre a mulher que se materializam no romance português. Narrativas, ficcionais ou não que, embora em tempos cronologicamente distintos, reproduzem um dizer sobre o feminino na esfera social, regularizando uma memória do dizer sobre a mulher na atualidade.

Como podemos observar nas análises, a mulher é significada a partir de um olhar masculino, produzindo sentidos acerca de um imaginário de mulher, com vistas a uma padronização de comportamento dos sujeitos contemporâneos, a partir de dizeres acerca dos lugares sociais estabilizados na sociedade. Nessa luta pela estabilização dos sentidos, os discursos sobre a mulher direcionam os sentidos para a instituição de práticas sociais intrinsecamente ligadas ao lugar que a mulher deve (ou não) ocupar na esfera social. A reprodução dos dizeres acerca de uma relação supostamente antagônica entre homem e mulher regulariza uma memória do dizer sobre a mulher submissa ao seu companheiro, que coloca em cheque a legitimidade dos movimentos em prol dos direitos das mulheres na sociedade contemporânea. Considerando que o sujeito se constitui na e pela linguagem (LACAN, 1999), os sentidos que direcionam para uma invisibilização da mulher, e suas demandas, corroboram um efeito de des-subjetivação da mulher na esfera social, regularizando uma memória do dizer não apenas sobre o feminino, mas sobre a posição que a mulher deve ocupar na esfera social: o lar, colocando em questão as conquistas políticas e sociais das mulheres na atualidade.

Em memória à luta histórica das mulheres pelos seus direitos, o Dia Internacional da Mulher é significado como um lugar de acolhimento de mulheres, um lugar de memória que traz em seu âmago o direito à voz, e muitas vezes de sua própria existência na esfera social. Neste trabalho, buscamos, ainda, rememorar as disputas travadas pelas mulheres em diferentes espaços discursivos que, a seu tempo, permitiram (e permitem) uma re-significação das suas posições no seio social, em resistência ao lugar que lhes é ideologicamente pré-determinado. 


\section{Referências}

BOAS, Franz. A mente do ser humano primitivo. Coleção Antropologia. Petrópolis-RJ: Vozes, 2011.

DAVALLON, Jean. 2007 [1983]. A imagem, uma arte de memória? In: ACHARD, Pierre et al.. Papel da memória. Campinas, SP: Pontes, 2007.

DICIONÁRIO DE SINÔNIMOS. Disponível em: <https://www.sinonimos.com.br/simular/.> Acesso em 26 fev. 2019.

DICIONÁRIO Priberam da Língua Portuguesa. Disponível em <https://dicionario.priberam.org/consultar.aspx>. Acesso em 28 dez. 2018.

FACINA, Adriana. Literatura e sociedade. Rio de Janeiro: Jorge Zahar, 2004.

GIORGENON, Daniela; ABRAHÃO E SOUSA, Lucília Maria; PACÍFICO, Soraya Maria Romano. Sujeito, corpo e um espelho (cibernético): a memória em imagem e em discurso. Revista Tempo Psicanalítico, Rio de Janeiro, v. 46.1, p. 81-97, 2014.

GREVES e manifestações ao redor do mundo pelos direitos das mulheres. Jornal do Brasil, Rio de Janeiro, 8 mar. 2018. Disponível em $<$ https://www.jb.com.br/index.php?id=/acervo/materia.php\&cd_matia=88633 $9 \&$ dinamico=1\&preview=1>. Acesso em 28 fev. 2019.

HERCULANO, Alexandre. A dama pé-de-cabra. Belém: UNAMA, s/d. Disponível em <http://www.nead.unama.br/>. Acesso em 4 dez. 2018.

LACAN, Jacques. O seminário livro 5: as formações do inconsciente (19571958). Rio de Janeiro: Jorge Zahar, 1999.

MARIANI, Bethania Sampaio Correa. O comunismo imaginário: práticas discursivas da imprensa sobre o PCB (1922-1989). 1996. 256f. Tese (doutorado) - Universidade Estadual de Campinas, Instituto de Estudos da Linguagem, Campinas. 
MCCHESNEY, Robert Waterman. Mídia global, neoliberalismo e imperialismo. In: MORAES, Dênis de. (Org.). Por uma outra comunicaçãomídia, mundialização cultural e poder. Rio de Janeiro: Record, 2003.

ORLANDI, Eni Puccineli As formas do silêncio no movimento dos sentidos. Campinas: Editora da Unicamp, 2007.

PÊCHEUX, Michel. Papel da memória. In: ACHARD, P. (Org.) Papel da memória. Campinas: Pontes, 1999.

PÊCHEUX, Michel. Semântica e discurso: uma crítica à afirmação do óbvio. Campinas: Editora da Unicamp, 1988.

PERROT, Michelle. As mulheres ou os silêncios da história. Bauru: EDUSC, 2005.

ROMÃO, Lucília Maria. O discurso sobre a mídia nos entremeios da narrativa de Saramago. Cadernos de Ciências Humanas - Especiaria, Ilhéus, v.10, n.17, jan./jun., 2007, p.215-245. Disponível em: $<$ http://www.uesc.br/revistas/especiarias/ed17/lucilia_maria_sousa_romao.p df $>$. Acesso em: 19 fev. 2019.

ROSARIO, Cláudia Cerqueira do. O lugar mítico da memória. Morpheus Revista Eletrônica de Ciências Humanas, Rio de Janeiro, v.1, n.1, 2002.

SOUZA, André. Mulheres fazem manifestação contra violência em praça de Cuiabá. G1, Cuiabá, 8 mar. 2017. Disponível em: <http://g1.globo.com/matogrosso/noticia/2017/03/mulheres-fazem-manifestacao-contra-violencia-empraca-de-cuiaba.html>. Acesso em: 27 dez. 2018.

THE UNIVERSITY of Queensland. Fryer Library Online Exhibition. International Womens Day, 8th March. Disponível em $<$ http://web.archive.org/web/20080721222502/https://www.library.uq.edu.au/ fryer/iwd/>. Acesso em 18 fev. 2019. 